\title{
AÇÕES DOCENTES EM AULAS DE FÍSICA DO ENSINO MÉDIO: UM OLHAR SOB A PERSPECTIVA ARGUMENTATIVA
}

\author{
TEACHING WORK IN PHYSICS CLASSES IN HIGH SCHOOL: A LOOK UNDER THE \\ ARGUMENTATIVE PERSPECTIVE
}

\author{
ENSEÑANZA DE TRABAJO EN LAS CLASES DE FÍSICA EN LA ENSEÑANZA \\ MEDIA: UNA MIRADA BAJO LA PERSPECTIVA ARGUMENTATIVA
}

\author{
Ariane Baffa Lourenço* \\ Pedro Donizete Colombo Júnior** \\ Gláucia Grüninger Gomes Costa ${ }^{\star \star \star}$
}

\begin{abstract}
Resumo: É fundamental que professores criem ambientes favoráveis à prática da argumentação em sala de aula, uma vez que esta colabora na aquisição da linguagem científica e possibilita desenvolver nos estudantes a capacidade de raciocinar e discutir problemas científicos. Nesta pesquisa analisamos as estratégias utilizadas por uma professora de Física do primeiro ano do Ensino Médio buscando identificar como as interações ocorridas em aula podem favorecer ou não a argumentação. As aulas foram gravadas em vídeo em uma escola pública do Estado de São Paulo e analisadas usando o modelo de Toulmin (2001) (identificação de elementos presentes nos argumentos), o padrão de Erduran Simon e Osborne (2004) (identificação da complexidade dos argumentos produzidos) e o modelo de Sá (2010) (identificação das interações ocorridas em aula). Também realizamos uma entrevista com a docente com o intuito de complementar os dados para a compreensão do problema investigado e propiciar um feedback para a mesma. Observamos que os argumentos produzidos em sala de aula, em sua maioria, eram formados apenas de dados e conclusão e que a postura da professora influenciou significativamente a maneira como estes ocorreram. Percebemos ainda que a professora interpreta o fato de os argumentos serem constituídos apenas por dois elementos do modelo de Toulmin como consequência da pouca habilidade e vontade dos alunos em se exporem, e não como o resultado de diferentes fatores que envolvem o tipo de abordagem de ensino realizada, os fatores intrínsecos aos sujeitos envolvidos e a postura da mesma como promotora da argumentação em aula.
\end{abstract}

Palavras chaves: Argumentação. Ensino de Física. Ensino Médio.

\begin{abstract}
It is fundamental that teachers promote an argumentative environment in the classroom, since this assists in the scientific language acquisition and enables students to develop the ability to reason and discuss scientific problems. In this research we analyzed the strategies used by a physics teacher trying to identify how the interactions occurring in the classroom can facilitate or not the argumentation. The classes were recorded on video in a public school in the state of São Paulo and analyzed using the model of Toulmin (2001) (identifying elements present in the arguments), the approach of Erduran,
\end{abstract}

\footnotetext{
* Doutora em Ciências: Ensino de Física pela Universidade de São Paulo. E-mail: arianebaffatutora@gmail.com

** Doutorando em Ensino de Física pela Universidade de São Paulo. Professor da Universidade Federal do Triângulo Mineiro (UFTM). E-mail: pedro.colombo.jr@gmail.com

*** Doutora em Física pela Universidade de São Paulo. E-mail: gggcosta@gmail.com
} 
Simon e Osborne (2004) (identifying the complexity of the arguments produced) and the model Sá (2010) (identifying the interactions occurring in class). We also conducted an interview with the teacher in order to understand the difficulties investigated and provide a feedback for her. We observed that the arguments brought in class mostly consisted only of data and conclusion and that the attitude of the teacher significantly influenced the way these occurred. We also perceived that the teacher interpreted the fact that the arguments being made up of only two elements of the Toulmin model as a consequence of the limited ability and willingness of students to expose themselves, and not as the result of different factors that involve the teaching approach performed, the intrinsic factors to the subjects involved and the attitude of the teacher as a promoter of argumentation in class.

Keywords: Argumentation. Physics Teaching. High School.

Resumen: Es fundamental que los profesores propicien ambientes favorables a la práctica de la argumentación en las clases, una vez que ésta colabora en la adquisición del lenguaje científico y posibilita desarrollar en los estudiantes la capacidad de razonar y discutir problemas científicos. En esta investigación se analizó las estrategias utilizadas por una profesora de Física del primer año de Enseñanza Media buscando identificar cómo las interacciones producidas en la clase pueden favorecer o no la argumentación. Las clases fueron grabadas en audio y vídeo en una escuela pública del Estado de São Paulo y analizadas utilizando el modelo de Toulmin (2001) (identificación de elementos presentes en los argumentos); el patrón de Erduran, Simon y Osborne (2004) (identificación de las interacciones producidas en la clase). También se realizó una entrevista con la docente para complementar los datos y propiciar un "feedback" para la comprensión del problema investigado. Se observó que la mayoría de los argumentos producidos en la clase estaban formados solamente por datos y conclusión y que la actitud de la profesora influjo significativamente en la manera como esto ocurrió. Se encontró, además, que la profesora interpreta el hecho de los argumentos constituidos solo por dos elementos del modelo de Toulmin como consecuencia de la poca habilidad y voluntad de los alumnos en expresarse, y no como el resultado de diferentes factores que involucran el tipo de abordaje de enseñanza realizada, de los factores intrínsecos a los sujetos implicados y de su postura como promotora de la argumentación en clase.

Palabras clave: Argumentación. Enseñanza de Física. Enseñanza Media.

\section{Considerações iniciais}

A linguagem ocorrida em sala de aula possui um papel fundamental na aquisição do conhecimento científico escolar em aulas de Ciências (SÁ; LINHARES, 2009; CAPECCHI; CARVALHO; SILVA, 2002; VILLANI; NASCIMENTO 2003). Para Lemke (1998), aprender Ciências significa se apropriar do discurso científico, ou seja, aprender como determinados termos se relacionam entre si e com o contexto em que estão inseridos, a fim de que seja produzida uma aprendizagem significativa. Essa perspectiva converge quanto à necessidade de ampliar o conceito de Educação em Ciências, atentando para o importante papel da linguagem nos processos de ensino e aprendizagem.

Desta maneira, entende-se que o conhecimento científico possui uma linguagem própria, capaz de tornar possível seu aprendizado e principalmente seu desenvolvimento. Ter domínio desta linguagem é essencial tanto para a prática da Ciência quanto para seu aprendizado (VILLANI; NASCIMENTO, 2003, SÁ; LINHARES, 2009; JIMÉNEZALEIXANDRE; BUSTAMANTE, 2003). Neste sentido, argumentar em aulas de Ciências torna-se um processo fundamental para compreender os conceitos e a natureza 
da Ciência (AUFSCHNAITER et al., 2008; CAAMAÑO; 2010). Na argumentação, processos de pensamento e raciocínio são explicitados, levando os estudantes a buscarem apoio para suas afirmações e convicções em evidências, com a finalidade de avaliar diferentes vieses do discurso.

Para que ocorra a argumentação em sala de aula é essencial que se desenvolvam atividades que façam sentido para os alunos. Além disso, é importante discutir questões relevantes para as Ciências, investigar e comparar soluções de diferentes pontos de vista e construir explicações coletivas para os fenômenos (JIMÉNEZ-ALEIXANDRE, 2010; GARCÍA DE CAJÉN; DOMÍNGUEZ CASTIÑEIRAS; GARCÍA-RODEJA, 2002). No entanto, é importante que as discussões propiciem conflitos cognitivos de modo que os alunos possam não apenas tomar consciência de suas ideias, mas também buscar razões para sustentá-las e compará-las com as ideias de seus pares, ou ainda refutar ideias contrárias.

Figura 1 - Modelo do padrão de argumentação de Toulmin.

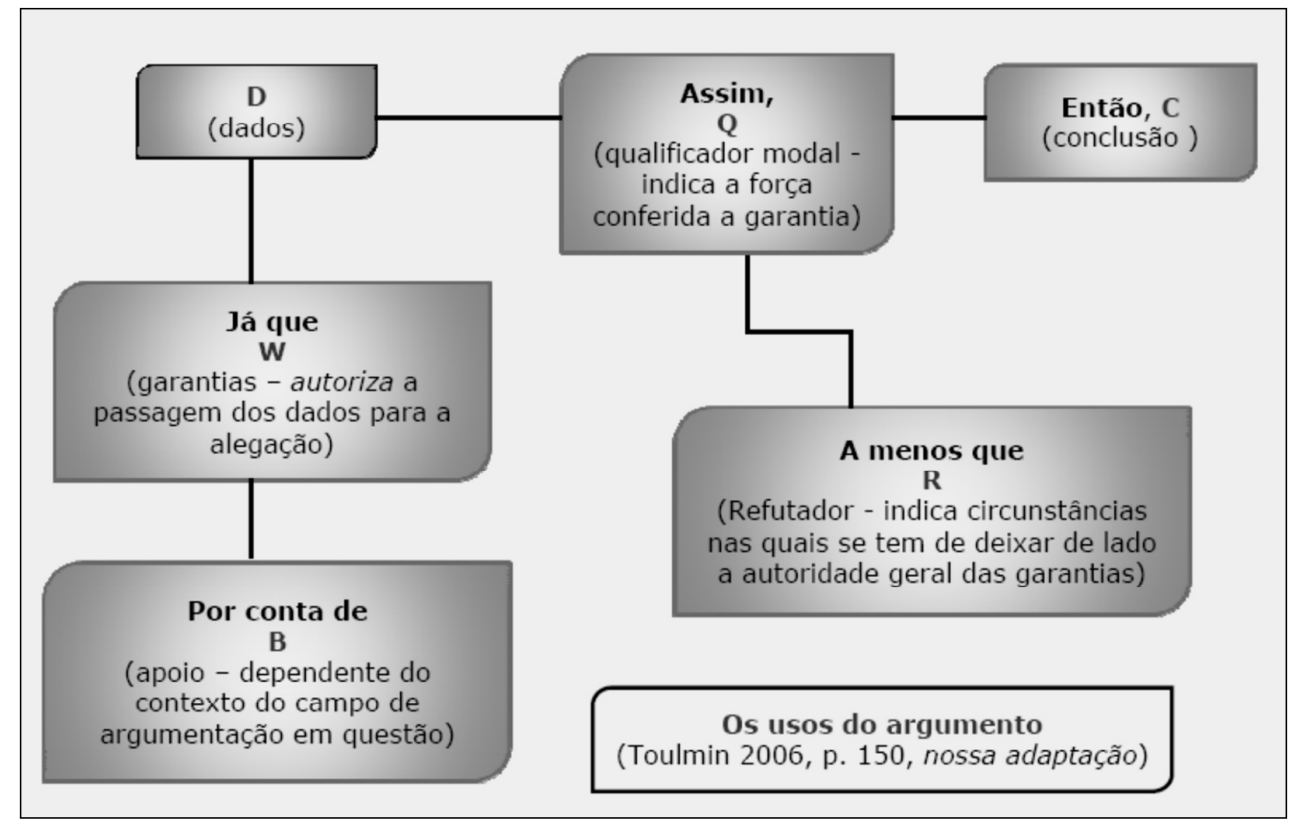

Fonte: Colombo Junior et. al., 2012

Muitas pesquisas da área de Ensino de Ciências apontam a importância de promover a argumentação durante as aulas (DRIVER; NEWTON; OSBORNE, 2000; JIMÉNEZ-ALEIXANDRE; BUGALLO RODRÍGUEZ; DUSCHL, 2000; CAPECCHI; CARVALHO; SILVA, 2002; DUSCHL; OSBORNE, 2002; ERDURAN, 2008; SASSERON, 2008; COSTA, 2008; SASSERON; CARVALHO, 2011). No entanto, há de se considerar também a importância de se analisar a qualidade e os elementos dos argumentos produzidos pelos alunos. Não basta que os alunos argumentem sobre determinado assunto, é preciso meios de se analisar a qualidade desta argumentação. Neste sentido, uma parte significativa da literatura de argumentação no Ensino de Ciências tem sido baseada nos trabalhos de Stephen Toulmin. 
Toulmin (2001), estudando a estrutura e a validade de argumentos, concluiu que há alguns elementos presentes na argumentação que são comuns a variados campos do conhecimento (campos invariáveis) enquanto outros diferem de acordo com o campo (campos dependentes). Toulmin traduziu tais elementos no que chamou de TAP (Toulmin's Argument Pattern), o qual pode ser visto na Figura 1.

Os dados (D) são informações com a finalidade de chegar à solução de um problema ou à comprovação de um enunciado (JIMÉNEZ-ALEIXANDRE, 2010). Embora às vezes se pense nos dados em termos de números e porcentagens, estes podem ser informações qualitativas não redutíveis a números, os quais, em algumas atividades, compõem as ideias chave. Assim, os dados podem ser caracterizados como dado fornecido (DF) - pelo professor, livro, texto ou roteiro de experimento - dado obtido (DO), o qual pode ser classificado como um dado empírico (DE), procedente, por exemplo, de uma experiência em laboratório (JIMÉNEZ-ALEIXANDRE, 2010), e dado hipotético (DH), fruto de hipóteses levantadas que fomentem discussões (VILLANI; NASCIMENTO, 2003; CAPECCHI; CARVALHO; SILVA 2000).

Entre os dados e a conclusão existe a justificativa (J), que, geralmente, são frases que apresentam uma razão aceitável para a conclusão proposta. Seu papel é mostrar que a conclusão que foi feita a partir dos dados é adequada e legítima. Para que as justificativas sejam asseguradas, há a necessidade do conhecimento básico/backing (B), representado por conhecimentos teóricos ou empíricos, modelos ou leis que as fundamentem (SÁ; LINHARES, 2009).

As condições necessárias para que uma justificativa seja válida ou não, são dadas pelos qualificadores modais (Q) ou pelas refutações (R), que complementam a "ponte" existente entre dado e conclusão (VILLANI; NASCIMENTO, 2003). Os qualificadores modais expressam o grau de certeza ou incerteza de um argumento e condições que supõem uma modificação do enunciado por meio de termos como "provavelmente” ou "previsivelmente”. Ligado aos qualificadores, muitas das vezes encontram-se os refutadores (R), condições capazes de invalidar ou refutar a conclusão (VILLANI; NASCIMENTO, 2003; JIMÉNEZALEIXANDRE, 2010).

Erduran, Simon e Osborne (2004) propõem que durante um processo argumentativo os argumentos produzidos pelos alunos podem ser analisados de acordo com sua complexidade. Assim, é possível avaliar a qualidade dos argumentos a partir da combinação dos componentes do modelo de Toulmin (2001), derivados das falas e textos produzidos pelos alunos. Os autores explicitam ainda que combinações que possuem o maior número de componentes do padrão de Toulmin são classificadas como um argumento mais elaborado, decaindo a ordem de complexidade à medida que decai a quantidade de componentes do modelo de Toulmin, o que podemos observar através do Quadro 1.

É importante enfatizar que as interações que ocorrem em sala de aula, tanto entre o professor e os alunos quanto entre os alunos, podem ser facilitadoras ou inibidoras da criação de ambientes argumentativos. Sobre este aspecto, Sá (2010), com base nos trabalhos de Newton (apud Sá, 2010), propõe um modelo de categorização para analisar as interações que ocorrem em um ambiente argumentativo de ensino. Como exposto no Quadro 2, o modelo proposto engloba três âmbitos de análise, sendo: forma de trabalho dos alunos (FTA), atividade dos alunos (AA) e interação professor-aluno (IPA). 
Quadro 1 - Ordem crescente de complexidade dos argumentos de acordo com o modelo de Erduran, Simon e Osborne (2004)

\begin{tabular}{|l|c|}
\hline \multicolumn{1}{|c|}{ Combinação dos elementos } & Código da combinação \\
\hline Conclusão/Dado/Justificativa & CDJ \\
\hline Conclusão/Dado/Justificativa/Backing (Conhecimento Básico) & CDJB \\
\hline Conclusão/Dado/Justificativa/Refutação & CDJR \\
\hline Conclusão/Dado/Justificativa/Qualificador Modal & CDJQ \\
\hline Conclusão/Dado/Justificativa/Backing (Conhecimento Básico)/Qualificador Modal & CDJBQ \\
\hline Conclusão/Dado/Justificativa/Backing (Conhecimento Básico)/Qualificador modal Refutador & CDJBQR \\
\hline
\end{tabular}

Quadro 2 - Relação dos aspectos de interação ocorridos em sala de aula observados no trabalho de Sá (2010)

\begin{tabular}{|c|c|}
\hline Âmbito & Atividade \\
\hline \multirow{4}{*}{ Forma de Trabalho dos Alunos (FTA) } & Atividade com a classe inteira \\
\hline & Atividade em pequenos grupos \\
\hline & Atividade individual \\
\hline & Outra \\
\hline \multirow{11}{*}{ Atividade dos Alunos (AA) } & Ouvindo uma explicação \\
\hline & Lendo \\
\hline & Realizando exercícios \\
\hline & Fazendo anotações \\
\hline & Realizando atividade aberta com lápis e papel \\
\hline & Observando uma demonstração \\
\hline & Realizando trabalho prático direcionado \\
\hline & Realizando trabalho prático livre \\
\hline & Preparando ou organizando o ambiente \\
\hline & Discutindo formalmente com o grupo \\
\hline & Outra \\
\hline \multirow{6}{*}{ Interação Professor-Aluno (IPA) } & Professor dando instruções \\
\hline & Professor explanando ideias científicas \\
\hline & Perguntas e respostas \\
\hline & Realizando atividades deliberativas \\
\hline & Aluno elaborando questões \\
\hline & Outra \\
\hline
\end{tabular}

O âmbito de análise "forma de trabalho dos alunos” (FTA) relaciona-se às maneiras como as aulas são desenvolvidas; o seguinte, “atividade dos alunos” (AA), compreende análise das atividades executadas pelos alunos; já a “interação professor-aluno" (IPA) procura analisar a existência e a maneira como ocorrem as interações entre professor e alunos. Visando obter uma classificação do tipo de interação ocorrida em sala de aula, certamente este modelo pode servir de subsídio para entender os argumentos ou a ausência destes em sala de aula.

A partir dos referenciais apresentados buscamos entender como se desenha a relação verbal entre uma professora e seus alunos, como se estabelecem as situações argumentativas em sala de aula e quais os fatores que a influenciam. 


\section{Metodologia}

Este trabalho remete ao contexto educacional de uma escola pública do estado de São Paulo, particularmente à análise das interações e das estratégias didático-pedagógicas com viés argumentativo utilizadas por uma professora de Física com mais de vinte anos de experiência docente. Algumas aulas da docente foram assistidas, e nosso recorte delimita a análise das aulas em que a professora trabalhou tópicos de Cinemática e Leis de Newton em uma turma do primeiro ano do Ensino Médio. Sendo os processos interativos e as estratégias de ensino ocorridas em sala de aula os pilares que sustentam a presente pesquisa, utilizamos uma filmadora posicionada na frente da sala, de modo a gravar o áudio e vídeo de todos os sujeitos da pesquisa. O intuito foi captar mais fidedignamente falas e movimentos dos alunos e da professora.

As gravações favoreceram a análise dos dados, visto que "há toda uma gama de gestos, expressões, entonações, sinais não verbais, hesitações, alterações de ritmo, enfim, toda uma comunicação não apenas verbal cuja captação é muito importante" (LÜDKE; ANDRÉ, 1986, p. 36-37). A gravação possibilita também a compreensão e validação do que foi anotado e observado durante os trabalhos de aplicação e discussão das atividades e obtenção de dados de investigações dessa natureza. A análise dos dados foi realizada em uma perspectiva qualitativa, pois se procurou interpretar e descrever a fala, os gestos e as ações da professora e dos alunos durante a aula.

Dos alunos presentes, 64\% participaram ativamente da aula, respondendo às perguntas propostas pela professora. Os demais mostraram desinteresse e não interagiram em nenhum momento. Os discursos produzidos pela professora e alunos durante as aulas foram analisados destacando os elementos estruturais do argumento com base no modelo de Toulmin, assim como de acordo com sua complexidade seguindo a proposta de Erduran, Simon e Osborne (2004). Foi considerado um argumento cada episódio em que se obtinha no mínimo um dado e uma conclusão. A interação ocorrida em sala de aula também foi analisada inicialmente de forma descritiva e depois usando o modelo apresentado no trabalho de Sá (2010) em que há elementos para a análise da interação.

É importante enfatizar que, devido à natureza dos dados obtidos, eles foram analisados por dois pesquisadores separadamente, que depois se reuniram para buscarem um consenso sobre o nível de concordância obtido. De posse dos resultados, uma entrevista foi realizada com a professora participante da pesquisa com o intuito de complementar os dados para a compreensão do problema investigado e propiciar um feedback a ela.

\section{Resultados}

Optamos por dividir a apresentação e discussão dos resultados em três momentos: a análise das estratégias usadas pela professora e das interações ocorridas durante a aula, a análise da argumentação e qualidade dos argumentos e uma (re)leitura dos processos argumentativos em aula: a visão da professora. Tal medida prende-se ao fato de podermos olhar para um mesmo dado com diferentes visões, englobando os pressupostos teóricos outrora discutidos.

\subsection{Análise das estratégias usadas pela professora e das interações ocorridas du- rante a aula}

Inicialmente, fomentados pelo modelo proposto por Sá (2010), realizamos a análise das gravações e dos dados coletados, com o objetivo de discutir o tipo de interação 
ocorrida em sala de aula, os estudos descritivos das estratégias utilizadas pela professora e o feedback dos alunos.

A forma de trabalho dos alunos (FTA) que ocorreu na maior parte das aulas foi a atividade com a classe inteira, em que a professora, para resgatar conceitos já discutidos e trabalhar novos, interagiu com os alunos por meio de questionamentos e explicações. Observamos também a ocorrência de atividades individuais, com a realização de uma lista de exercícios que contemplava o conteúdo estudado, e de atividades em pequenos grupos, em que os alunos resolveram exercícios. Quanto às atividades dos alunos (AA), enquanto os alunos refletiam sobre os conceitos, discutiam formalmente com o grupo para responder os questionamentos realizados nos exercícios.

No âmbito da interação professoraluno (IPA), observamos a ocorrência de perguntas e respostas, atividade fomentada pela professora durante todo o desenvolver das aulas por meio de interações dialógicas com os alunos. Notamos também a atividade em que o professor explana ideias científicas, a qual teve maior frequência quando ocorria a inserção de novos conceitos científicos. Por último, o professor dando instrução, principalmente na solicitação de tarefas e exercícios aos alunos.

Em relação ao tipo de interação dialógica ocorrida, observou-se que a professora geralmente formulava perguntas aos alunos e discutia as respostas enunciadas por eles. O retorno da professora às colocações dos alunos nem sempre era direto, ou seja, em alguns momentos a professora evidenciava que a resposta dada estava errada, reformulava a pergunta e aguardava uma nova manifestação dos alunos, fato observado no Quadro 3.

Quadro 3 - Episódio em que a professora questiona os alunos sobre o “como calcular” a velocidade no Movimento Uniformemente Variado (MUV)

\begin{tabular}{|c|c|l|}
\hline Turno & Participantes & \multicolumn{1}{|c|}{ Discurso } \\
\hline 10 & Professora & $\begin{array}{l}\text { Hein? Como eu calculo a velocidade para o Movimento Uniformemente } \\
\text { Variado? }\end{array}$ \\
\hline 11 & Aluno 2 & Aceleração. \\
\hline 12 & Professora & $\begin{array}{l}\text { Velocidade! Eu quero calcular a velocidade do Movimento Uniformemente } \\
\text { Variado. }\end{array}$ \\
\hline 13 & Aluno 3 & [Inaudível]. \\
\hline 14 & Aluno 4 & Delta $v$ [variação da velocidade] sobre delta $t$ [variação do tempo]? \\
\hline 15 & Professora & Eu quero saber a velocidade para o Movimento Uniformemente Variado. \\
\hline 16 & Aluno 5 & Velocidade inicial mais $a$ [aceleração] vezes $t$ [tempo]. \\
\hline 17 & Professora & Ah, velocidade inicial mais $a$ vezes $t$ ! \\
\hline
\end{tabular}

Tendo inicialmente como resposta “aceleração” (Aluno 2), a professora, sem afirmar a veracidade da resposta, guiou a sala por meio de novas colocações, fato constatado com a resposta do Aluno 4. Nota-se que a professora cessou de repetir a pergunta apenas quando a resposta correta, desejada por ela, foi enunciada pelo Aluno 5. É importante perceber que o aluno não foi questionado sobre como definir o conceito velocidade, não sendo possível perceber se ele decorou uma fórmula matemática ou realmente interpreta o conceito corretamente. 
Fica evidente no episódio acima que as respostas erradas fornecidas pelos alunos foram ignoradas pela professora, não as usando para serem discutidas e argumentadas com a sala. Tal atitude impossibilitou saber o motivo pelo qual os alunos deram tais respostas, a criação de um conflito cognitivo de ideias com os demais alunos e a construção de uma explicação correta para o fenômeno estudado. Em geral, a maioria das respostas enunciadas pelos alunos pautou-se de afirmações sem justificativas. Talvez este fato tenha ocorrido devido, principalmente, à maneira como a pergunta foi realizada, que não favoreceu os processos argumentativos. Em alguns poucos momentos, ainda que de modo tênue, a professora mudou a estratégia que vinha utilizando (Iniciação-RespostaAvaliação) e passou a valorizar e atentar para as respostas dos alunos, como observado no Quadro 4.

Quadro 4 - Episódio em que a professora questiona os alunos quanto às respostas

\begin{tabular}{|c|c|l|}
\hline Turno & Participantes & \multicolumn{1}{c|}{ Discurso } \\
\hline 91 & Professora & Empurrão para onde? \\
\hline 92 & Aluno 5 & Pra frente. \\
\hline 93 & Professora & $\begin{array}{l}\text { O ônibus sai e você sente um empurrão para frente? É isso? Todos } \\
\text { concordam? [Professora dá um tempo aos alunos e exalta a entonação da } \\
\text { voz no trecho grifado]. }\end{array}$ \\
\hline 94 & Professora & $\begin{array}{l}\text { Vocês estão sentados, o ônibus arranca e vocês sentem um empurrão para } \\
\text { frente. E quando ele breca? }\end{array}$ \\
\hline 96 & Aluno 3 & [Inaudível]. \\
\hline 97 & Professora & $\begin{array}{l}\text { Não, é o contrário. } \\
\text { corpo? Para onde? }\end{array}$ \\
\hline 98 & Aluno 6 & Para trás. \\
\hline
\end{tabular}

Diante da resposta do aluno 5, a professora reelabora a questão fazendo uso da resposta dele e simultaneamente instiga a participação dos alunos. Tal postura traz o efeito desejado, ou seja, a participação dos alunos e uma contrarresposta à primeira questão: “Não, é o contrário” (Aluno 6). É importante ressaltar que neste episódio não houve a possibilidade de muitas discussões, pois a entonação da voz da professora no turno 93 já dava indícios de que a resposta do aluno 5 estava errada, o que gerou naturalmente uma nova resposta, desta vez contrariando a do colega, sendo, no entanto, uma resposta sem justificativa.
A princípio, a mudança na entonação da voz pode passar despercebida, porém para alguns alunos esta também pode ser um agente inibidor de sua participação, uma vez que pode significar para ele imposição, mesmo que inconsciente, por parte do professor ou confirmação de seu erro. É importante mostrar para o aluno que ele errou, porém é mais importante ainda mostrar que este erro não é sinônimo de fracasso, mas apenas representa aquilo que ainda não aprendeu. Em outras palavras, “ideias errôneas não devem representar incapacidade ou entrave para o processo de ensino-aprendizagem, e sim parte de sua evolução e desenvolvimento" (COLOMBO JUNIOR, 2010, p. 162). 
No turno 122 (Quadro 5), a professora questiona os alunos sobre o que acontece quando um inseto (figurado pela professora como "bichinhos") vem voando e se choca com um automóvel. Observa-se na transcrição que este problema possibilitou aos alunos argumentarem, mesmo que de maneira comedida.

Quadro 5 - Episódio em que a professora apresenta um problema aos alunos sobre a lei de ação e reação

\begin{tabular}{|c|c|c|}
\hline Turno & Participantes & Discurso \\
\hline 122 & Professora & $\begin{array}{l}\text { Eu aplico uma força na parede, a parede aplica uma força em mim, isto é o } \\
\text { princípio da ação e reação. Aí eu pergunto para vocês o seguinte: olha, vocês já } \\
\text { perceberam no fim da tarde que muitas vezes tem aqueles bichinhos [insetos] } \\
\text { que vêm e batem no vidro lá do carro, do ônibus, do caminhão? O que acontece } \\
\text { com eles? }\end{array}$ \\
\hline 123 & Professora & Eles voltam? \\
\hline 124 & Aluno 6 & Voltam. \\
\hline 125 & Professora & Voltam? \\
\hline 126 & Aluno 6 & Não. \\
\hline 127 & Professora & O que acontece? \\
\hline 128 & Aluno 3 & Morrem. \\
\hline 129 & Professora & $\begin{array}{l}\text { Eles morrem, não é? Ele não chega lá, bate e estoura, não é assim? Mas por } \\
\text { quê? O princípio não fala que a toda ação tem que ter uma reação igual e de } \\
\text { sinal [sentido] contrário? Por que o bichinho morre e o vidro não faz nada? }\end{array}$ \\
\hline 130 & Aluno 6 & Por causa que [...] ele tem uma força maior. \\
\hline 131 & Professora & $\begin{array}{l}\text { Olha lá, o que diz o princípio? A ação e reação têm que ser iguais, as forças são } \\
\text { iguais. Por que o bichinho morre? }\end{array}$ \\
\hline 132 & Aluno 5 & Porque ele não conseguiu aguentar a força. \\
\hline 133 & Professora & Ele não conseguiu? \\
\hline 134 & Aluno 5 & Suportar a força. \\
\hline 135 & Professora & Por que ele não conseguiu suportar a força? \\
\hline 136 & Aluno 7 & Porque ele não conseguiu reagir ao vidro. \\
\hline 137 & Professora & $\begin{array}{l}\text { Não, ele reagiu, ação e reação ocorrem, o colega falou [...] [que] ele não con- } \\
\text { seguiu suportar a força. É isso? }\end{array}$ \\
\hline 138 & Aluno 5 & É, ele aplicou uma força, mas não conseguiu suportar. \\
\hline 139 & Professora & Por que ele não conseguiu? \\
\hline 140 & Professora & Hein? \\
\hline 141 & Aluno 7 & A força voltou para ele. \\
\hline 142 & Professora & Por que ele não conseguiu suportar a força e o vidro conseguiu? \\
\hline 143 & Aluno 5 & Porque ele é mais sensível que o vidro. \\
\hline
\end{tabular}

A resposta dada pelo Aluno 5 no turno 132, apesar de “correta”, não cessa a discussão, ou seja, a professora aproveitou a efervescência das discussões e conduziu a aula fazendo que os alunos pensassem na resposta fornecida: “o colega falou [...] [que] ele não conseguiu suportar a força. É isso?” (turno 137). Tal postura da professora levou o Aluno 5 a se posicionar dando uma justificativa à resposta por ele enunciada: "É, ele aplicou uma força, mas não conseguiu suportar” (turno 138). De modo um pouco 
mais tímido, porém não menos importante, o Aluno 7 também apresentou uma justificativa para a morte do inseto, o que é evidenciado no turno 141.

Outro aspecto observado durante a aula foi a transformação de um termo enunciado pelo Aluno 5 para um termo mais apropriado e adequado ao contexto estudado.
Nota-se no turno 144 (Quadro 6) que a professora se apropria do termo "sensível" (turno 143) e o transforma em "menos resistente”. Observa-se que essa transformação parece ter sido incorporada pelos alunos, ou seja, os mesmos passam a usá-la em suas colocações, como pode ser visto no turno 149.

Quadro 6 - Episódio em que a professora transforma um termo enunciado pelo aluno para um mais apropriado ao contexto estudado

\begin{tabular}{|c|c|l|}
\hline Turno & Participantes & \multicolumn{1}{|c|}{ Discurso } \\
\hline 144 & Professora & $\begin{array}{l}\text { Ah, porque ele é mais sensível. Mais sensível, vamos traduzir isto como sendo } \\
\text { mais ou menos resistente. [...] Vem cá, se vocês forem lá, na lousa, e derem um } \\
\text { soco lá na parede, o que vai acontecer? }\end{array}$ \\
\hline 145 & Vários alunos & Vai quebrar a mão. \\
\hline 146 & Professora & Vai quebrar a mão. E a parede? \\
\hline 147 & Vários alunos & Nada. \\
\hline 148 & Professora & E por que quebra a mão e a parede nada? \\
\hline 149 & Aluno 1 & Porque ela é mais resistente. \\
\hline
\end{tabular}

Quadro 7 - Episódio em que a professora questiona os alunos sobre a terceira Lei de Newton e utiliza gestos juntamente com a expressão oral

\begin{tabular}{|c|c|l|}
\hline Turno & Participantes & \multicolumn{1}{|c|}{ Discurso } \\
\hline 111 & Professora & $\begin{array}{l}\text { Sem ela não funciona, ou seja, é básico, é essencial. Este princípio fala o } \\
\text { seguinte: a resultante de todas as forças sobre um corpo vai ser exatamente } \\
\text { o produto da massa que um corpo possui pela aceleração que ele vai adquirir. } \\
\text { Nada mais é do que a definição de força que nós tivemos. [...] Porque ele é } \\
\text { fundamental, porque através dele nós podemos quantificar, [...] saber quanto } \\
\text { vale a força que se está aplicando. [...] Se chama Terceira Lei de Newton ou } \\
\text { Princípio da Ação e Reação, o que vai dizer este Princípio? A toda ação existe } \\
\text { uma reação igual e de sentido contrário. Como assim? Me diga uma coisa, } \\
\text { peguem a mão e aperte na carteira. O que vocês sentem? Vamos lá. Vamos } \\
\text { fazer. [professora gesticulando]. }\end{array}$ \\
\hline 112 & Professora & O que vocês sentem? Nada? \\
\hline 113 & Aluno 3 & Dor no braço. \\
\hline 114 & Professora & Por que dor no braço? \\
\hline 115 & Aluno 2 & [Inaudível]. \\
\hline 116 & Professora & Mas o que sua mão, sua palma da mão está sentindo? [Não] sente nada? \\
\hline 117 & Aluno 6 & Parece que a mesa está empurrando a mão. \\
\hline & & $\begin{array}{l}\text { Parece que a mesa está empurrando a mão, é isso? Exatamente isso, eu apliquei } \\
\text { uma ação na mesa, uma força na mesa, e o que a mesa faz? Reage? Como? } \\
\text { Aplicando uma força igual e de sentido contrário, é por isso que parece que a } \\
\text { mão está sendo empurrada para cima. Não é isso? Se eu empurrar a parede o } \\
\text { que está acontecendo? }\end{array}$ \\
\hline 118 & Professora \\
\hline
\end{tabular}


Com a expressão oral, foram identificados vários momentos em que a professora utilizou-se de gestos para dar ênfase a uma situação estudada, como observado no episódio dos turnos 111 e 118 (Quadro 7).

Ao longo do período de gravação, observamos também outras ações da professora, como escrever no quadro, gesticular pedindo aos alunos que respondessem sua pergunta e pedir a eles que utilizassem o caderno e o livro didático. É importante enfatizar que em inúmeros momentos a expressão facial, assim como a entonação de voz da professora, foram facilmente decodificadas e entendidas pelos alunos, o que demonstra, no mínimo, certa ressonância nas interações ocorridas em aula de aula.

\subsection{Análise da argumentação e qualidade dos argumentos}

Conforme já foi mencionado anteriormente, Erduran, Simon e Osborne (2004) explicitam que durante o processo argumentativo os argumentos produzidos pelos alunos podem ser analisados de acordo com sua complexidade (Quadro 1) e traduzidos em qualidade argumentativa. Identificamos durante as aulas 21 padrões relacionados à argumentação, seguindo o padrão de Toulmin. Destes, 14 eram compostos pela combinação do tipo "conclusão-dado" e 7 seguiam a tríade "conclusão-dado-justificativa”. Tal resultado evidenciou uma tendência nas aulas analisadas em que os alunos comumente construíam argumentos somente compostos por dados e conclusões.

Especificamente no que tange aos dados, que eram fornecidos pela professora, entendemos que estes perfaziam a combinação de três elementos: informação, questão e situação, sendo: "informação + questão" (IQ); “situação + questão” (SQ) e "informação + situação + questão” (ISQ). No gráfico da Figura 2, apresentamos os padrões identificados em nossa análise e interpolados pelos três diferentes elementos dos dados.

Figura 2 - Combinações dos elementos dos argumentos produzidos

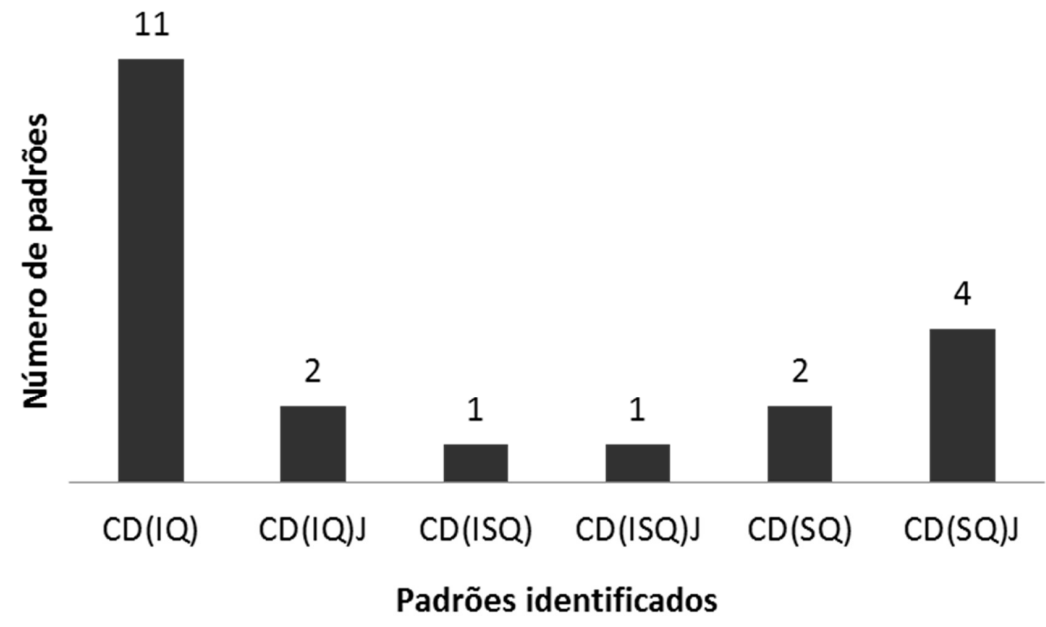

Legenda: CD(IQ): Conclusão e Dado (Informação e Questão);

CD(IQ)J: Conclusão e Dado (Informação e Questão), Justificativa;

CD(ISQ): Conclusão, Dado (Informação, Situação e Questão);

CD(ISQ)J: Conclusão, Dado (Informação, Situação e Questão), Justificativa;

CD(SQ): Conclusão, Dado (Situação e Questão);

CD(SQ)J: Conclusão, Dado (Situação e Questão), Justificativa. 
Na combinação de um dado composto por uma IQ, a professora apresentava uma informação referente à temática, como pode ser observado no exemplo da Figura 3. Neste exemplo, a professora define o Princípio Fundamental da Dinâmica para os alunos e em seguida os questiona em relação ao termo Fundamental da expressão, obtendo uma resposta diretiva e sem justificativa. Esta combinação (IQ) foi realizada em 13 dos padrões identificados.

Figura 3 - Esquema com exemplo de dado formado por informação e questão

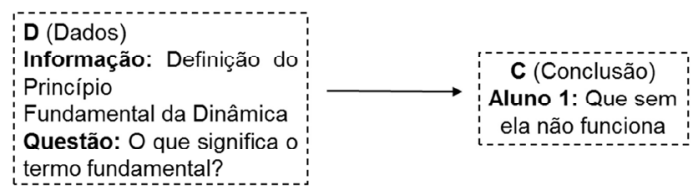

A segunda combinação representada apenas por situação e questão (SQ) foi identificada em 6 padrões. Como exemplo, na Figura 4, a professora oferece aos alunos uma situação na qual estão no interior de um ônibus no momento em que ele arranca. Em seguida lança a questão: “o que vocês sentem?” Mesmo sem a professora fornecer informações adicionais, nota-se que, sendo esta uma situação vivencial dos alunos, eles espontaneamente expressam uma justificativa, potencializando o processo argumentativo em sala de aula.

Figura 4 - Esquema com exemplo de dado formado por situação e questão

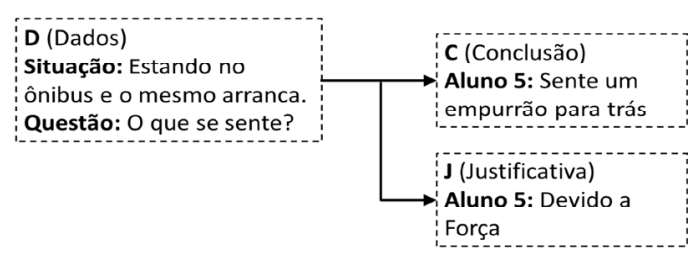

Na combinação entre informação, situação e questão (ISQ), presente em dois padrões, além dos aspectos acima mencionados, a professora acrescenta após a informação uma situação hipotética, que foi a vontade de movimentar uma mesa (Figura 5). A situação posta pela professora levou os alunos a buscarem justificativas para suas respostas (conclusão), propiciando um processo argumentativo inicial.

Figura 5 - Esquema com exemplo de dado formado por informação, situação e questão

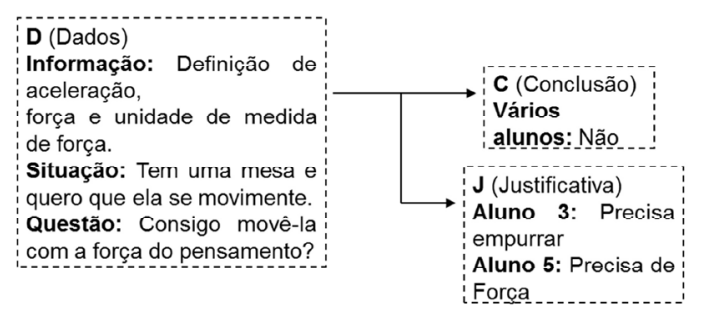

Esta análise evidencia que o processo argumentativo em sala de aula, por ser dialógico, necessita da constante inserção de elementos novos que favorecem a tomada de decisões. Fica evidente que quando a professora traz para as aulas situações vivenciadas pelos alunos e informações adicionais, o processo de argumentação é facilitado o que possibilita a formação de um argumento formado não somente por Dado e Conclusão, mas por outros elementos estruturais do modelo de Toulmin, que no caso dos episódios analisados foi a Justificativa (J).

\subsection{Uma (re)leitura dos processos argumentativos em aula: a visão da professora}

Ao final da análise e discussão dos dados, agendamos uma entrevista semiestruturada com a professora colaboradora da pesquisa de modo a investigar a visão dela sobre 
sua própria prática docente e apresentar os dados da presente pesquisa. Nesta entrevista, buscamos ouvir da professora a relação das estratégias utilizadas por ela durante as aulas e o desenvolvimento argumentativo realizado, particularmente os argumentos elaborados pelos alunos.

A professora se coloca motivada e interessada em promover espaços para os alunos argumentarem em suas aulas. $\mathrm{Na}$ transcrição a seguir, é interessante perceber na fala da docente sua preocupação com o conhecimento prévio dos alunos no momento do trabalho argumentativo (trecho em negrito). Outro destaque foi sua preocupação em relação ao processo de ensino e aprendizagem dos alunos voltados para a vivência social (trecho em itálico):

[Considerações da docente em relação ao questionamento se esta promove argumentação em sala de aula:] Sim, tanto que sempre procuro desenvolver o conteúdo através de questionamentos que vai unindo o já conhecido e preparando para que eles consigam entender o novo. É possível, através da argumentação, observar o desenvolvimento do raciocínio do aluno. Penso que os alunos, como cidadãos, devem se preparar para a vida, saber se colocar diante de um problema, argumentar sobre as possibilidades de resolução e através delas tomar decisões.

Em relação às estratégias utilizadas para estimular a argumentação dos alunos, a professora aponta que seu objetivo era promover questionamentos e fazer experiências de pensamento com o conteúdo abordado. Assim, não apenas explicita o trabalho argumentativo, via questionamentos, mas também traz à tona sua preocupação em inovar a didática, utilizando metodologias que fossem diferentes da convencional, neste caso “experiências de pensamento”. Experiências de pensamento (ou experiências mentais) podem ser definidas como conjuntos de raciocínios lógicos sobre experiências que, a princípio, não podem ser realizadas no nosso dia a dia, mas cujas consequências podem ser exploradas pela imaginação nas diversas áreas do conhecimento (FABRIS; PRADO, 2009).

Em relação a grande quantidade de argumentos formados por Dado e Conclusão, a professora aponta que este fato é devido os alunos se sentirem envergonhados e com medo de se expressarem durante as aulas.

[Considerações da docente em relação à justificativa dos argumentos dos alunos, em sua maioria, serem formados por dados e conclusão:] Eu penso que os alunos têm muita dificuldade e medo em se exporem. Muitas vezes faço a pergunta e espero minutos em silêncio para que algum deles responda alguma coisa.

Além do sentimento de vergonha e medo em falar em público, a professora também atribui como fator de empecilho ao ambiente argumentativo em sala de aula à concepção que os alunos têm das salas de aula, ou seja, uma visão de que o aluno deve ser agente passivo, escutar as explicações do professor e copiar o conteúdo, sem argumentar. Aponta também que outra barreira a ser enfrentada para o favorecimento de um ambiente argumentativo é a dificuldade que os alunos possuem de exporem suas ideias. Para a docente, tal situação tem suas raízes no início da escolarização, na qual os alunos desde muito cedo internalizam a ideia de que as aulas são regidas apenas pelo saber docente. Este tipo de posicionamento é preocupante, visto que acaba por formar cidadãos que não se expressam ou que têm receio de emitir sua opinião, o que distancia em muito da desejada formação científica de cidadãos críticos para a sociedade atual. 
[Considerações da docente em relação a aspectos que dificultam a argumentação dos alunos em sala de aula:] Primeiro, como é normal a qualquer ser humano, eles têm a dificuldade de exporem suas ideias, também a dificuldade de saber que alguém pode fazer brincadeira com sua fala [...] mesmo eu colocando que não admito brincadeiras com as perguntas e respostas de qualquer aluno, temos que notar que nos dias atuais temos alguns alunos que são inclusão. Segundo, muitos deles trazem consigo a ideia de que aula é apenas escutar e copiar. Trabalho muito em grupo para que eles possam se soltar mais e se inserirem na disciplina. Poucos são os alunos que se sentem confortáveis a se exporem.

Entendemos que uma das formas de mudar este quadro está na inserção de atividades argumentativas em sala de aula, em que os alunos possam trabalhar com explicitações de diferentes pontos de vista, perceber suas ideias e lacunas e (re)construir seus pensamentos. Além disso, as atividades argumentativas podem possibilitar a formação de um cidadão responsável, capaz de participar nas decisões sociais. Quanto à avaliação da professora sobre a análise de suas aulas, ela considera que em suas aulas se preocupa em formar o educando para a vida, sempre trazendo exemplos do cotidiano imediato dos alunos (trecho em negrito).

[Considerações da docente em relação as suas aulas analisadas:] Essas foram aulas teóricas, onde se teve a primeira parte de revisão dos conceitos estudados anteriormente, e depois introduzido conceitos novos. Ela se deu por meio de questionamentos, tentando fazer com que ocorresse uma participação dos alunos, a fim de que eu pudesse ter noção dos conhecimentos que ainda não estavam claros para eles, pois seriam necessários para que compreendessem o conteúdo novo a ser trabalhado. Nesta aula, coloquei alguns exemplos do cotidiano para que os alunos pudessem pensar, sentir e trazer mais para o concreto a teoria envolvida. Por fim, foi solicitado que fizessem uma lista de exercícios que tanto continham exercícios teóricos conceituais como exercícios que necessitavam de cálculos. Nesta parte deixei que optassem por fazer sozinhos [...] muitos são os alunos que preferem assim [...] ou em grupo conversando e trocando ideias.

A professora ainda destaca que o processo argumentativo não é de fácil utilização em sala de aula. Para que ele ocorra deve haver uma interação entre o professor e os alunos, onde os alunos devem estar dispostos a participarem, e o professor a deixá-los participar. Essa participação nem sempre é fácil, pois é uma característa da adolescência ter medo de se expor, de errar. Os alunos muitas vezes não percebem que essa exposição é necessária para seu próprio crescimento, pois é através do uso de argumentos para defender suas ideias que ocorre a construção do conhecimento.

\section{Considerações finais}

Esta pesquisa buscou analisar se as estratégias utilizadas por uma professora de Física do primeiro ano do Ensino Médio possibilitaram um ambiente propício à argumentação. Observamos que a estratégia mais utilizada pela professora foi o diálogo diretivo: a professora pergunta, e os alunos respondem, com algumas retomadas e discussões. Garcez e Loder (2005) denominam este tipo de atividade como uma estratégia econômica para a exposição e verificação do conhecimento. Nas aulas, os alunos tiveram poucos momentos para discussão de suas ideias com os colegas e para examinaram suas decisões. 
Uma análise mais profunda das interações ocorridas revela que no decorrer da aula predominou a atividade com a classe inteira, quando a professora tentava resgatar conceitos já discutidos e trabalhar novos conceitos, interagindo com os alunos por meio de questionamentos. Além disso, os alunos participaram em atividades em que discutiam formalmente com o grupo, ouviam uma explicação e faziam anotações e realizavam exercícios. Tal análise possibilitou termos uma visão das interações que ocorreram na aula, o que serviu de base para entendermos os resultados em relação à argumentação, a qual geralmente foi formada por dados (formados pelas combinações dos elementos informação, situação e questão) e conclusão, fato que está relacionado à interação da professora com os alunos, uma vez que em muitos momentos a mesma não possibilitava espaços para um processo argumentativo efetivo em sala de aula.

Fica evidente na fala da professora que esta interpreta este quadro como uma consequência da pouca habilidade e vontade dos alunos em se exporem, e não como o resultado de diferentes fatores que envolvem desde o tipo de abordagem de ensino realizada, passando por fatores intrínsecos aos sujeitos envolvidos, até a postura da mesma como promotora da argumentação em sala de aula.

Diante dos resultados, salientamos a importância de se trabalhar com os professores as estratégias argumentativas e sua influência no processo, destacando os elementos que constituem um bom argumento. Além disso, torna-se fundamental que o professor tenha um momento de reflexão de sua própria prática docente, baseada em referenciais teóricos.

\section{Referências}

AUFSCHNAITER, C. V. et al. Arguing to learn and learning to argue: Case studies of how students' argumentation relates to their scientific knowledge. Journal of Research in Science Teaching, v. 45, n. 1, p. 101-131, 2008.

CAAMAÑO, A. Argumentar em ciências. Alambique. Didáctica de las Ciencias Experimentales, v. 63, p. 5-10, 2010.

CAPECCHI, M. C. V.; CARVALHO, A. M. P.; SILVA, D. Argumentação dos alunos e o discurso do professor em uma aula de física. Ensaio - Pesquisa em Educação em Ciências, v. 2, n. 2, p. 189-208, 2000.

- Relações entre o discurso do professor e a argumentação dos alunos em uma aula de física. Ensaio - Pesquisa em Educação em Ciências, v. 2, n. 2, p. 1-15, 2002.

COLOMBO JUNIOR, P. D. et al. Ensino de física nos anos iniciais: análise da argumentação na resolução de uma atividade de conhecimento físico. Investigações em Ensino de Ciências, v. 17, n. 2, p. 489-507, 2012.

COLOMBO JUNIOR, P. D. A percepção da gravidade em um espaço fisicamente modificado: uma análise à luz de Gaston Bachelard. Dissertação - Faculdade de Educação e Instituto de Física, Universidade de São Paulo, 2010. Disponível em: <http://www.teses.usp.br/ teses/disponiveis/81/81131/tde-04082010112227/fr.php>.

COSTA, A. Desenvolver a capacidade de argumentação dos estudantes: um objetivo pedagógico fundamental. Revista Iberoamericana de Educación, v. 46, n. 5, p. 1-8, 2008. Disponível em: <http://www. 
rieoei.org/deloslectores/2233Costa.pdf>. Acesso em: 15 jan. 2012

DRIVER, R.; NEWTON, P. Establishing the norms of scientific argumentation in classrooms. Paper prepared for presentation at the ESERA Conference, Rome, Italy, 2-6 Sep. 1997.

DRIVER, R.; NEWTON, P.; OSBORNE, J. Establishing the Norms of Scientific Argumentation in Classrooms. Science Education, v. 84, p. 287-312, 2000.

DUSCHL, R. A.; OSBORNE, J. Supporting and Promoting Argumentation Discourse in Science Education. Studies in Science Education, v. 38, p. 39-72, 2002.

ERDURAN, S.; SIMON, S.; OSBORNE, J. Tapping into argumentation: developments in the application of Toulmin's argument pattern for studying science discourse. Science Education, v. 88, n. 6, p. 915-933, 2004.

ERDURAN, S. Methodological Foundations in the Study of Science Classroom Argumentation. In: JIMÉNEZALEIXANDRE, M.; ERDURAN, S. (Ed.), Argumentation in science education: perspectives from classroom-based research. Springer: Dordrecht, 2008.

FABRIS, G. S. L.; PRADO, F. D. As experiências no pensamento (Gedankenexperiment) e suas influências no ensino de física. In: CONGRESSO DE INICIAÇÃO CIENTÍFICA DA UNESP, 21, São José do Rio Preto, São Paulo, p. 95169517, 2009. Disponível em: <http://prope. unesp.br/xxi_cic/27_39561734818.pdf > . Acesso em: 2 fev. 2012.

GARCÍA DE CAJÉN, S.; DOMÍNGUEZ CASTIÑEIRAS, J. M.; GARCÍA-RODEJA F. E. Razonamiento y argumentación en ciencias: diferentes puntos de vista en el currículo oficial. Enseñanza de las Ciencias, v. 20, n. 2, p. 217-228, 2002.

GARCEZ, P. M.; LODER, L. L. Reparo iniciado e levado a cabo pelo outro na conversa cotidiana em português do Brasil. DELTA, v. 21, n. 2, p. 279-312, 2005.

JIMÉNEZ-ALEIXANDRE, M. P.; BUGALLO RODRÍGUEZ, A.; DUSCHL, R. A. "Doing the lesson" or "doing science": argument in high school genetics. Science Education. v. 84, p. 757-792, 2000.

JIMÉNEZ-ALEIXANDRE, M., P.; BUSTAMANTE, J. D. Discurso de aula y argumentación en la clase de ciencias: cuestiones teóricas y metodológicas. Enseñanza de las ciencias, v. 21, n. 3, p. 359-370, 2003.

JIMÉNEZ-ALEIXANDRE, M. P. 10 ideas clave: competencias en argumentación y uso de pruebas. Barcelona: Graó, 2010.

LEMKE, J. L. Teaching all the languages of science: words, symbols, images, and actions. In: SCHOOL OF EDUCATION. Conference on Science Education. BARCELONA, 1998. Disponível em: <http://academic. brooklyn.cuny.edu/education/jlemke/sci-ed. htm>. Acesso em: 2 mar. 2011.

LÜDKE, M.; ANDRÉ, M. Pesquisa em educação: abordagens qualitativas. São Paulo: EPU, 1986.

MORTIMER, E. F.; SCOTT, P. Atividade discursiva nas salas de aula de ciências: uma ferramenta sociocultural para analisar e planejar o ensino. Investigações em Ensino de Ciências, v. 7, n. 3, p. 283-306, 2002.

NEWTON, P., DRIVER, R.; OSBORNE, J. "The place of argumentation in the pedagogy of school science”. International Journal of Science Education. v. 21, n. 5, p. 553576, 1999. 
SÁ, L. P. Estudo de casos na promoção da argumentação sobre questões sóciocientíficas no Ensino Superior de Química. 300 f. (Tese de Doutorado em Ciências) Centro de Ciências Exatas e de Tecnologia, Departamento de Química, Universidade Federal de São Carlos, São Carlos, 2010.

SÁ, L. P.; LINHARES, S. Q. Estudo de casos no ensino de química. São Paulo: Átomo, 2009.

\section{SASSERON, L. H. Alfabetização científica} no Ensino Fundamental: Estrutura e Indicadores deste processo em sala de aula. Tese de doutorado, Faculdade de Educação, Universidade de São Paulo, São Paulo, 2008.

SASSERON, L. H.; CARVALHO, A. M. P. Construindo argumentação na sala de aula: a presença do ciclo argumentativo, os indicadores de Alfabetização Científica e o padrão de Toulmin. Ciência e Educação, v. 17, n. 1, p. 97-114, 2001.

TOULMIN, S. Os usos do argumento. Tradução de Reinaldo Guarany. São Paulo: Martins Fontes, 2001.

VILLANI, C. E. P.; NASCIMENTO, S. S. A argumentação e o ensino de ciências: uma atividade experimental no laboratório didático de física do ensino médio. Investigações em Ensino de Ciências, v. 8, n. 3, p. 187-209, 2003.

Enviado em: 28. Fev. 14

Aceito em: 26. Maio. 14 